\title{
Sero-Prevalence of $\boldsymbol{H}$. pylori Antibodies among Asymptomatic Rural Population in Bauchi State, Nigeria-A Preliminary Study
}

\author{
Mohammed Alkali', Kenneth 0. Okon 2*, Yusuf B. Jibrin'1, Sabo Umar'1, Abdulrazak Toyin ${ }^{3}$, \\ Godiya I. Darie1, Farouk Buba ${ }^{4}$, Sulayman T. Balogun' ${ }^{5}$, Binta Lasan ${ }^{6}$ \\ ${ }^{1}$ Department of Internal Medicine, Abubakar Tafawa Balewa University Teaching Hospital, Bauchi, Nigeria \\ ${ }^{2}$ Department of Medical Microbiology, Federal Medical Centre, Makurdi, Nigeria \\ ${ }^{3}$ Department of Chemical Pathology, Abubakar Tafawa Balewa University Teaching Hospital, Bauchi, Nigeria \\ ${ }^{4}$ Department of Medicine, College of Medical Sciences, University of Maiduguri, Maiduguri, Nigeria \\ ${ }^{5}$ Department of Clinical Pharmacology and Therapeutics, College of Medical Sciences, University of Maiduguri, Maiduguri, Nigeria \\ ${ }^{6}$ Department of Microbiology, Abubakar Tafawa Balewa University Teaching Hospital, Bauchi, Nigeria \\ Email: *okonkenneth@gmail.com
}

How to cite this paper: Alkali, M., Okon, K.O., Jibrin, Y.B., Umar, S., Toyin, A., Darie, G.I., Buba, F., Balogun, S.T. and Lasan, B. (2020) Sero-Prevalence of $H$. pylori Antibodies among Asymptomatic Rural Population in Bauchi State, Nigeria-A Preliminary Study. Open Journal of Gastroenterology, 10, 301-310.

https://doi.org/10.4236/ojgas.2020.1011029

Received: September 18, 2020

Accepted: November 14, 2020

Published: November 17, 2020

Copyright $\odot 2020$ by author(s) and Scientific Research Publishing Inc. This work is licensed under the Creative Commons Attribution International License (CC BY 4.0).

http://creativecommons.org/licenses/by/4.0/

cc) (i) Open Access

\begin{abstract}
Helicobacter pylori infection is a major public health problem globally, with high prevalence in developing countries associated with poor sanitation, low standard of living, urban-rural disparity and increased gastrointestinal pathologies. This preliminary study determined the seroprevalence of $H$. pylori infection among asymptomatic rural population and association of sociodemographic variables on the result outcome. A total of 250 asymptomatic volunteered participants were screened for $H$. pylori antibodies, using rapid immunochromatographic strips. $44.8 \%(112 / 250)$ were seropositive, and showed increased prevalence with the age group, <15 years (8.0\%), 18 - 39 years $(23.5 \%)$ and $40-65$ years $(12.0 \%)$ with no significant difference. High prevalence among males, 88 (35.2) compared to $24(9.6)$ females $(\mathrm{p}<0.228)$. Significant association was observed with marital status, high prevalence among married participants 63 (25.0) followed by singles, 41 (16.4) $(\mathrm{p}<$ 0.010). Similarly, significant prevalence was observed among participants with non-formal education, 60 (24.0) followed by primary education, 21 (8.4) $(\mathrm{p}<0.51)$. While non-salary earners accounted for $79(31.6)(\mathrm{p}<0.244)$. The $H$. pylori seropositivity of $44.8 \%$ is relatively low in region with previous reports of high prevalence and predisposing risk factors. Further studies are needed to evaluate the effect of environmental and occupational risk factors for better epidemiological understanding of $H$. pylori infection and a template for intervention measures.
\end{abstract}




\section{Keywords}

Seroprevalence, $H$. pylori, Antibodies, Asymptomatic, Rural Population, Bauchi

\section{Introduction}

Helicobacter pylori infection is a major public health problem globally with increasing incidence of gastric and duodenal diseases [1] [2]. It is a gram-negative coccobacilli bacterium that colonises gastric mucosa and progress resulting in gastritis, duodenal ulcer, gastric ulcer, MALT lymphoma [3] [4]. The WHO reports that $H$. pylori virulence factors play a major causal role in the development of gastric cancer [5]. According to IACR, H. pylori is identified as group I carcinogen responsible for gastric cancer [6], which is the third most common cancer globally with high incidence in China and South Korea [7] [8] but low in sub-Saharan Africa with high seroprevalence [9] [10].

Globally, $50 \%$ of the world population is infected with $H$. pylori infection [1] [8]. In developing countries, acquisition of $H$. pylori infection occurs at childhood stage that may persist/or resolve due to cohort effect/or may progress into adulthood resulting in symptomatic manifestation, with the prevalence increased with age [8] [11] [12]. Substantial variations have been reported in $H$. pylori prevalence globally. There is high prevalence in developing countries ranging between 50\% - 90\%, particularly among rural population [8] [13] [14] [15] in contrast to low prevalence of between $30 \%$ and $50 \%$ in developed countries [1], dependent on the level of urbanization, sanitation, degree of hygiene, socio-economic status, cultural practices of pre mastication of food, overcrowding due to living within a small space, and poor educational background [1] [8] [16].

The route of $H$. pylori transmission is still not clearly defined, but oral-oral, oral-fecal and intrafamilial are identified as major means of transmission [15] [16]. These are facilitated by exposure to risk factors such as low standard of hygiene, low living standard, poor sanitation, contaminated water, food overcrowding educational background socio-economic status and demographic variables [16] [17]. In Nigeria, serological screening of $H$. pylori antibodies in different population had revealed varied seroprevalence rates from as low as $15 \%$ in Maiduguri [18], 35\% in Warri [19] to as high as 92\% in Maiduguri [14].

Diagnostic methods for detection of $H$. pylori infection are classified into invasive and non-invasive. Invasive methods involve endoscopy procedure followed by histological analysis, culture, or PCR considered as "gold standard". The non-invasive methods include serology, urea breath test and stool antigen and are mostly used for mass screening of $H$. pylori infection for epidemiological surveillance and evaluation of infection for eradication. The drawback of serological screening of $H$. pylori antibodies is possible overestimation of positive result. However serological method with enzyme immunosorbent assay method 
of IgG gives comparative sensitivity and specificity level with other invasive methods [19] [20].

Bauchi state is one of the 6 administrative states in northeastern Nigeria, with no documented epidemiological data on $H$. pylori infection either at hospital or community setting, thus, creating an epidemiological information gap, in accessing the public health implication of the infection and template for eradication strategy. Although an unpublished data of dyspepsia patients who presented for endoscopic procedure per clinic day at gastroenterology/hepatology unit of Abubakar Tafawa Balewa Teaching Hospital, Bauchi (ATBUTH) indicated an upward trend over the years, majority of these patients resides outside the state capital, which point to possible increased seroprevalence of $H$. pylori in the rural area affirming the urban-rural population disparity of $H$. pylori infection [8] [21]. Baseline epidemiological information becomes imperative for public health assessment and template for possible treatment and management approach. Based on this information, we decided to conduct a preliminary study on serological screening of $H$. pylori antibodies among asymptomatic rural population and assess the association of sociodemographic variables on the result outcome in a rural settlement of Bauchi state, Nigeria.

\section{Methodology}

The descriptive cross-sectional study was conducted in a rural community of Faggo in Shira local government area of Bauchi state, between July and September 2018. Geographically, Faggo is located on $11^{\prime} 22^{\circ}$ and $11^{\prime} 57^{\prime}$ East, within the Sahel savanna region. Majority of the populace are mainly farmers engaged in petty farming and livestock rearing, while some few civil servants who work with the local government area. The settlement pattern is constituted of old architectural structures mixed with few modern structure, Basic amenity care facilities, like pipe born water and sanitation facilities are not adequate. Among the common cultural practices is the communal sharing of meals, eating from the same plate and sharing utensils. The study protocol was approved by Abubakar Tafawa Balewa Teaching Hospital (ATBUTH) institutional review board. Study participants recruitment was on voluntary basis, through the assistance of community and religious leaders involved in the sensitization, awareness and public health education on the importance of the study. The study participants were clinically reviewed by the authors [US, DGI] of clinical conditions such as nausea, heartburn, abdominal pain, and other signs and symptoms susceptive of dyspepsia, that served as exclusion criteria. The standardized questionnaire and informed consent forms were administered by the authors [US, DG], which include the following information age, gender, marital status, educational background, occupation, while basic monthly income classification of the study participants was based on the federal government minimum wage template.

Five millimeters of venous blood was collected aseptically into pre-labelled specimen bottle, and transported to the Department of Chemical Pathology, ATBUTH, Bauchi. The samples were allowed to clot, retract, and centrifuged at 
15,000 rpm for 10 minutes and sera separated into sample bottle for analysis. Serological detection of $H$. pylori antibodies was carried out using One Step Anti-H. pylori Rapid Test (Colloidal Gold, manufactured in the USA), a lateral flow immunochromatographic screening test. The test is based on the reaction of recombinant antigen of $H$. pylori used in test band as captured material and gold conjugate react with the antibodies in the serum to form a labelled complex. The complex is captured by antigen in the test zone of the membrane producing a visible pink-rose color band within 15 - 20 minutes of the reaction. The test analysis, two drops of study participants serum was transferred into the sample well, a drop of reagent buffer added to the sample well and reaction read between 15 - 20 minutes. Appearance of one band in the control region is indicative of negative result, while appearance of two bands in the test and control region is a positive result.

\section{Data Analysis}

Sociodemographic and seropositivity data were analyzed using SPSS version 21.0, in descriptive frequency with values expressed in means, frequency and percentage. Association between the categorical variable and seropositivity of $H$. pylori was determined by chi-square test. The level of significance was set at $\mathrm{p}<0.05$.

\section{Result}

The 250 asymptotic rural participants screened for $H$. pylori antibodies, comprised of 216 males and 34 females with male to female ratio of $1: 1.63$, and mean age of $25.60+10.35$ years (age range of 5 - 66 years), 112 (44.8\%) were H. pylori seropositive. The sociodemographic variables and seropositivity of $H$. pylori antibodies (Table 1), showed increased seropositivity with age with no statistically significant difference observed $(\mathrm{p}<0.106),<15$ years $(20,8.0 \%), 18-39$ years $(89,23.6 \%)$ and $40-65$ years $(30,12.0)(\mathrm{p}<0.106)$. Seropositivity of males participants $88(35.2 \%)$ was four times higher than those of females, 24 (9.6\%) female ( $\mathrm{p}<0.223$ ). Significant association was observed with marital status, high seropositivity observed among the married participants, 63 (25.2\%) followed by singles 41 (16.4) ( $\mathrm{p}<0.010)$. Similarly, significant association was observed with education background, high prevalence among non-formal educational background, 60 (24.0) followed by primary education $21(8.4)(\mathrm{p}<0.051)$. Socioeconomic variables, high seropositivity was observed among non-monthly earners, 79 (31.6) $(\mathrm{p}<0.244)$.

\section{Discussion}

Most documented studies of $H$. pylori infection had focused on symptomatic cases in urban population, with relatively few studies among rural population. To our knowledge, this is the first report of serological screening of H. pylori antibodies among asymptomatic rural population in the study area. The study findings had provided a baseline data necessary for further studies aimed at better evaluation and possible eradication strategies. 
Table 1. Sociodemographic variables and seroprevalence of $H$. pylori.

\begin{tabular}{|c|c|c|c|c|}
\hline Variables & Total no tested & $\begin{array}{c}\text { No of } \\
\text { seropositive (\%) }\end{array}$ & $\begin{array}{c}\text { No of } \\
\text { seronegative (\%) }\end{array}$ & $\mathrm{p}$-value \\
\hline \multicolumn{5}{|l|}{ Age-group } \\
\hline$<18$ years & 76 & $20(8.0)$ & $56(22.3)$ & \\
\hline $18-39$ & 104 & $59(23.6)$ & $45(18.0)$ & 0.106 \\
\hline $40-65$ & 58 & $30(12.0)$ & $28(11.2)$ & \\
\hline$>65$ & 12 & $3(1.2)$ & $9(3.6)$ & \\
\hline \multicolumn{5}{|l|}{ Gender } \\
\hline Male & 216 & $88(35.2)$ & $128(51.2)$ & 0.228 \\
\hline Female & 34 & $24(9.6)$ & $10(4.0)$ & \\
\hline \multicolumn{5}{|l|}{ Marital status } \\
\hline Single & 97 & $41(16.4)$ & $56(22.4)$ & \\
\hline Married & 123 & $63(25.2)$ & $60(24.0)$ & 0.010 \\
\hline Divorce & 15 & $5(2.0)$ & $10(4.0)$ & \\
\hline Window & 11 & $31.2)$ & $8(3.2)$ & \\
\hline Widower & 3 & - & $3(1.2)$ & \\
\hline \multicolumn{5}{|c|}{ Educational background } \\
\hline Non-formal & 108 & $30(12.0)$ & $28(11.2)$ & \\
\hline Primary & 84 & $21(8.4)$ & $63(25.2)$ & 0.051 \\
\hline Secondary & 40 & $45(18.0)$ & $25(10.0)$ & \\
\hline Tertiary & 18 & $16(6.4)$ & $2(0.8)$ & \\
\hline \multicolumn{5}{|l|}{ Basic Income } \\
\hline Non-salary earner & 176 & $79(31.6)$ & $97(38.8)$ & \\
\hline$<\mathrm{N} 18,000$ & 52 & $23(9.2)$ & $29(11.6)$ & \\
\hline $18,000-35,000$ & 15 & $8(3.2)$ & $7(2.8)$ & 0.244 \\
\hline $35,000-70,000$ & 5 & $1(0.4)$ & $4(1.6)$ & \\
\hline $70,000-120,000$ & 1 & $1(0.4)$ & & \\
\hline$>120,000$ & 1 & & $1(0.4)$ & \\
\hline
\end{tabular}

In this study, the overall $H$. pylori seropositivity of $44.8 \%$ may be considered to be low when compared to $90.2 \%$ reported in Maiduguri, in the same geographical region with similar socio-cultural and religious practice [14]. Other studies with higher prevalence were, $72.3 \%$ in rural population of Benin republic [8], two studies conducted among adults and children population in Brazil, 84\% vs $87 \%$ and $77 \%$ vs $62 \%$ [22] [23] and $70.6 \%$ in Iran [24]. However, our study level is comparable to the levels reported in other studies, $41.8 \%$ in rural Nepal 
population [25] 43\% in Iraq [17] and 48.3\% in South South Nigeria [19]. It is however, higher than levels reported in other studies, $15 \%$ in Maiduguri, North east Nigeria [18], 27.6\% in Cameroon [26], 33.0\% in Puerto Rico [27], 37.5\% in Lagos South western Nigeria that employed the urea breath test [28] and 39.4 in Iraq [29]. This observed variation in the prevalence may be due to geographical location, level of exposure to risk factors like poor standard of hygiene and sanitation, lower socio-economic status and detection method employed.

Association between sociodemographic variables and $H$. pylori infection have been well documented [8] [27]. Primarily, the $H$. pylori infection is acquired at childhood, persists in the system and progresses up to adulthood depending on the cohort effect and immune status of the individual, and the prevalence increased with age [8] [12] [15] [27] [30]. In our study, children $<15$ years, seroprevalence increased from $8 \%$ to $23.6 \%$ among adult age group 18 - 39 years and $12.0 \%$ among 40 - 65 years, which is consistent with the findings in other studies [8] [31]. The prevalence level among children group in our study is lower when compared to other studies, $82.3 \%$ was reported among 5 - 10 years subjects in Maiduguri [14], 68.2\% - 75.8\% within age group of 2 - 5 years and 14 - 15 years in Benin republic [8]. However, similar low prevalence had been reported in other studies, $12.5 \%$ in Pakistan [17], 7\% - 33\% in Oman [29] and 14\% in Ghana [30]. This predisposes to intrafamilial transmission, particularly among mother and children (Alimajiri) - these are children seeking non-formal Islamic education [8] [17] [32] [33]. We are rather surprised by the low H. pylori seroprevalence recorded in our study area considering religious practice that allows young children to seek non-formal Islamic education which expose them to unhygienic environment, contaminated foods and water although such children did not feature among our study subjects and the design of the study did not allow for such details from the study questionnaire. However, as part of their culture engaged in communal eating with sharing of utensils. Despite, the predisposing risk factors the reason for low seroprevalence is rather unclear, which requires further evaluation.

There are documented data that support gender influence on $H$. pylori infection prevalence [8] [17] [19] [26] [28], which varies with study design and population. However, there is no biological evidence to support the gender difference. In this study, $H$. pylori prevalence of males was four times higher than females (35.2\% vs $9.6 \%$ ), with no significant difference, which is in agreement with other studies [8] [33]. In contrast, other studies had reported high prevalence among females [19] [29] The major reason that might be responsible for the high number of males study participants in our study, may be due to the fact that the males constituted the high population of study participants, which is also a reflection of socio-cultural and religious practices in the study area.

Socio-economic status and educational background of the study participants, are known indicators of public health education knowledge, awareness and preventive approach, associated with the level of good sanitation and personal hy- 
giene [8] [17] [27]. In our study, significant association was observed between seropositivity and marital status $(\mathrm{p}<0.010)$ and educational background ( $\mathrm{p}<$ 0.051) of the study participants. Of the marital status, high seroprevalence was observed among married participants, 63 (25.2\%) followed by singles 41 (16.6). Common norm in the study area, is polygamy and large family size leaving within small household leading to overcrowding, communal living which involves sharing of households item that may facilitate intra-familial transmission of infection [12] [32], As documented in other studies, the common practice of pre-mastication of food for children by mothers can serve as means of transmission [32] [33]. The effect of overcrowding on $H$. pylori infection has been well documented, but its influence as a risk factor of $H$. pylori infection is dependent on socio-economic status of the family as low $H$. pylori prevalence is associated with high income family household [8].

In addition to socio-economic status, the level of education, particularly low educational background is associated with high prevalence of $H$. pylori infection [8] [17] [27]. In our study, significant association was observed between educational background of study participants and $H$. pylori infection $(\mathrm{p}<0.05)$, with high prevalence recorded among study participants with non-formal educational background $(60,24.0 \%)$, consistent with other studies [8] [17] [27]. However, the level of educational attainment and $H$. pylori infection is dependent on exposure to the risk factors and socioeconomic status in the community Assessing the socio-economic status and $H$. pylori infection level, we determined the basic monthly income and $H$. pylori seropositivity, high seropositivity was recorded among non-salary earners $79(31.6 \%)$, findings that are consistent with other studies [8] [27]. The findings are a reflection of socio-cultural practice that encourages polygamy and family living within small household that could encourage intrafamilial transmission and poor sanitation [8] [17] [27].

Though our study had focused on seroprevalence and sociodemographic factors, nevertheless, the findings had provided an insight on baseline epidemiological information of $H$. pylori infection among asymptomatic rural population that can serve as template for further studies. While this study had public health significance, there are limitations which include, non-evaluation of risk factors such as environmental and occupational activities that may impact the seroprevalence outcome and the serodetection technique employed in the study. As the ELISA assay of $H$. pylori IgG antibodies is known to give similar degree of sensitivity and specificity with the gold standard assay [20].

\section{Conclusion}

The $H$. pylori infection prevalence of $44.8 \%$ recorded in this study is relatively low in the community with high predisposing risk factors. This seroprevalence raises some epidemiological questions that required further comprehensive studies aimed at assessing risk factors of both environmental and occupational activities on seroprevalence of $H$. pylori. 


\section{Acknowledgements}

We acknowledged the support of community, religious leaders and study participants of Faggo community and member of staff of Chemical Pathology of ATBUTH for technical and analysis of the samples and success of the study.

\section{Conflicts of Interest}

The authors declare no conflicts of interest regarding the publication of this paper.

\section{References}

[1] Hooi, J.K.Y., Lai, W.Y., Ng, W.K., Michael, M.Y., Suen, F.E., Tanyingoh, U.D., Malfertheiner, P., et al. (2017) Global Prevalence of Helicobacter pylori Infection: Systematic Review and Meta-Analysis. Gastroenterology, 153, 420-429. https://doi.org/10.1053/j.gastro.2017.04.022

[2] Peleteiro, B., Bastos, A., Ferro, A. and Lunet, N. (2014) Prevalence of Helicobacter pylori Infection Worldwide: A Systematic Review of Studies with National Coverage. In: Kaunitz, J. and Keeffe, M., Eds., Digestive Diseases and Sciences, Springer, Berlin, 1698-1709. https://doi.org/10.1007/s10620-014-3063-0

[3] Riegg, S.J., Dunn, B.E. and Blaser, M.J. (1995) Microbiology and Pathogenesis of Helicobacter pylori. In: Blaser, M.J., Ed., Infections of the Gastrointestinal Tract, Raven Press, New York, 535-550.

[4] McColl, K.E.L. (1997) Helicobacter pylori: Clinical Aspects. Journal of Infection, 34, 7-13. https://doi.org/10.1016/S0163-4453(97)80003-5

[5] World Gastroenterology Organization (2011) Global Guideline: Helicobacter pylori in Developing Countries. Journal of Digestive Diseases, 12, 319-326. https://doi.org/10.1111/j.1751-2980.2011.00529.x

[6] IARC (1994) IARC Monograph on the Evaluation of Carcinogenic Risks to Humans. Schistosomes, Liver Flukes and Helicobacter pylori, 177-240.

[7] You, W.C., Blot, W.J., Li, J.Y., et al. (1993) Precancerous Gastric Lesions in a Population at High Risk of Stomach Cancer. Cancer Research, 53, 1317-1321.

[8] Aguemon, B.D., Struelens, M.J., Massougbodji, A. and Ouendo, E.M. (2005) Prevalence and Risk-Factors for Helicobacter pylori Infection in Urban and Rural Beninese Populations. Clinical Microbiology and Infection, 11, 611-617. https://doi.org/10.1111/j.1469-0691.2005.01189.x

[9] Tanih, N.F., Ndip, L.M., Clarke, A.M., et al. (2010) An Overview of Pathogenesis and Epidemiology of Helicobacter pylori Infection. African Journal of Microbiology Research, 4, 426-436.

[10] Campbell, D.I., Warren, B.F., Thomas, J.E., Figura, N., Telford, J.L. and Sullivan, P.B. (2001) The African Enigma: Low Prevalence of Gastric Atrophy, High Prevalence of Chronic Inflammation in West African Adults and Children. Helicobacter, 6, 263-267. https://doi.org/10.1046/j.1083-4389.2001.00047.x

[11] Fallone, C.A. (1999). Determinants of Ethnic or Geographical Differences in Infectivity and Transmissibility of Helicobacter pylori. Canadian Journal of Gastroenterology and Hepatolog, 13, 251-255. https://doi.org/10.1155/1999/132197

[12] Weyermann, M., Rothenbacher, D. and Brenner, H. (2009) Acquisition of Helicobacter pylori Infection in Early Childhood: Independent Contributions of Infected Mothers, Fathers and Siblings. American Journal of Gastroenterology, 104, 182-189. 
https://doi.org/10.1038/ajg.2008.61

[13] Holcombe, C., Omotara, B.A., Eldridge, J. and Jones, D.M. (1992) Helicobacter pylori, the Most Common Infection in Africa: A Random Serological Survey. American Journal of Gastroenterology, 87, 28-30.

[14] Holcombe, C., Tsimiri, S., Eldridge, J. and Jones, D.M. (1993) Prevalence of Antibody to Helicobacter pylori in Children in Northern Nigeria. Transactions of the Royal Society of Tropical Medicine and Hygiene, 87, 19-21. https://doi.org/10.1016/0035-9203(93)90403-D

[15] Ndip, R.N., Malange, T.A.E., Ojongokpoko, J.E.A., Luma, H.N., Malongue, A., Akoachere, J.F.K., Ndip, L.M., MacMillan, M. and Weaver, L.T. (2008) Helicobacter pylori Isolates Recovered from Gastric Biopsies of Patients with Gastro-Duodenal Pathologies in Cameroon: Current Status of Antibiogram. Tropical Medicine \& International Health, 13, 848-854. https://doi.org/10.1111/j.1365-3156.2008.02062.x

[16] Mentis, A., Lehours, P. and Mégraud, F. (2015) Epidemiology and Diagnosis of $\mathrm{He}$ licobacter pylori Infection. Helicobacter, 20, 1-7. https://doi.org/10.1111/hel.12250

[17] AL-Mashhadany, D.A., Ismael, L.Q. and Zaki, A.M. (2018) Seroprevalence of Helicobacter pylori among Human in Erbil Governorate, Kurdistan Region, Iraq. Research Journal of Life Sciences, Bioinformatics, Pharmaceutical and Chemical Sciences, 4, 268-280.

[18] Balogun, S.T., Egwu, M.Q., Akanmu, A.O. and Okon, K.O. (2018) Sero-Prevalence of Helicobacter pylori and Pre-Hospital Medication among Nigerians with and without Symptoms Suggestive of Peptic Ulcer in Maiduguri. IOSR Journal of Dental and Medical Sciences (IOSR-JDMS), 17, 22-28.

[19] Omosor, O.H., Ibeh, I.N., Adejumo, B.I.G., Abdulkadir, U.I., Dimkpa, U., Uchuno, G.A., Oke, O.M., Abdulkadir, R.L., Hamidu, M.V. and Emmanuel, A.M. (2017) Seroprevalence of Helicobacter pylori Infection and Risk Factors among Asymptomatic Subjects in Delta State, Nigeria. Advances in Microbiology, 7, 641-652. https://doi.org/10.4236/aim.2017.79050

[20] Wen, X., Wen, D., Yang, Y., Chen, Y., Wang, G. and Shan, B. (2017) Urban-Rural Disparity in Helicobacter pylori Infection-Related Upper Gastrointestinal Cancer in China and the Decreasing Trend in Parallel with Socioeconomic Development and Urbanization in an Endemic Area. Annals of Global Health, 83, 444-462. https://doi.org/10.1016/j.aogh.2017.09.004

[21] Yilmaz, Ö., Şen, N., Küpelioğlu, A.A. and Şimşek, İ. (2006) Detection of H. pylori Infection by ELISA and Western Blot Techniques and Evaluation of Anti CagA Seropositivity in Adult Turkish Dyspeptic Patients. World Journal of Gastroenterology, 12, 5375-5378. https://doi.org/10.3748/wjg.v12.i33.5375

[22] Oliveira, A.M.R., Rocha, G.A., Queiroz, D.M.M., Barbosa, M.T. and Silva, S.C. (1999) Prevalence of $H$. pylori Infection in a Population from the Rural Area of Aracual, MG, Brazil. Revista de Microbiologia, 30, 59-61. https://doi.org/10.1590/S0001-37141999000100012

[23] Oliveira, A.M.R., Queiroz, D.M.M., Rocha, G.A. and Mendes, E.N. (1994) Seroprevalence of Helicobacter pylori in Children of Low Socioeconomic Level in Belo Horizonte, Brazil. American Journal of Gastroenterology, 89, 2201-2204.

[24] Alizadeh, A.H.M., Ansari, S., Ranjbar, M., Shalmani, H.M., Habibi, I., Firouzi, M. and Zali, M.R. (2009) Seroprevalence of Helicobacter pylori in Nahavand: A Population Based Study. Eastern Mediterranean Health Journal, 15, 129-135. https://doi.org/10.26719/2009.15.1.129

[25] Kawasaki, M., Kawasaki, T., Ogaki, T. Itoh, K., Kobayashi, S., Yoshimizu, Y., Aoya- 
gi, K., Iwakawa, A., Takahashi, S., Sharma, S. and Acharya, G.P. (1998) Seroprevalence of Helicobacter pylori Infection in Nepal: Low Prevalence in an Isolated Rural Village. European Journal of Gastroenterology \& Hepatology, 10, 47-50. https://doi.org/10.1097/00042737-199801000-00009

[26] Abongwa, L.E., Samje, M., Antoine, K.S., Elvis, M., Benardette, L., Kuchonde, P. and Ronald, F. (2017) Knowledge, Practice and Prevalence of Helicobacter pylori in the North West Region of Cameroon. Clinical Biotechnology and Microbiology, 4, 135-143.

[27] González-Pons, M., Soto-Salgado, M. and Sevilla, J. (2018) Seroprevalence of Helicobacter pylori in Hispanics Living in Puerto Rico: A Population-Based Study. Helicobacter, 23, e12453. https://doi.org/10.1111/hel.12453

[28] Smith, S., Fowora, T.J.M., Palamides, P., Ngoka, F., Bamidele, M. and Lesi, O. (2018) Clinical and Socio-Demographic Risk Factors for Acquisition of Helicobacter pylori Infection in Nigeria. Asian Pacific Journal of Cancer Prevention, 19, 1851-1857.

[29] Al-Sinani, S., Al-Mulaabed, S.W., Al-Naamani, K. and Al-Sharji, H. (2017) Helicobacter pylori Infection in Omani Children. Helicobacter, 22, 306-311.

https://doi.org/10.1111/hel.12379

[30] Awuku, A.Y., Simpong, D.L., Alhassan, I.K., Tuoyire, D.A., Afaa, T. and Adu, P. (2017) Prevalence of Helicobacter pylori Infection among Children Living in a Rural Setting in Sub-Saharan Africa. BMC Public Health, 17, Article No. 360. https://doi.org/10.1186/s12889-017-4274-z

[31] Kivi, M., Tindberg, Y. and Sorberg, M. (2003) Concordance of Helicobacter pylori Strains within Families. Journal of Clinical Microbiology, 41, 5604-5608. https://doi.org/10.1128/JCM.41.12.5604-5608.2003

[32] Konno, M., Fujii, N., Yokota, S., Sato, K., Takahashi, M. and Sato, K. (2005) Five-Year Follow-Up Study of Mother-to-Child Transmission of Helicobacter pylori Infection Detected by a Random Amplified Polymorphic DNA Fingerprinting Method. Journal of Clinical Microbiology, 43, 2246-2250. https://doi.org/10.1128/JCM.43.5.2246-2250.2005

[33] Escobar, M.L. and Kawakami, E. (2004) Evidence of Mother-Child Transmission of Helicobacter pylori Infection. Arquivos de Gastroenterologia, 41, 239-244.

https://doi.org/10.1590/S0004-28032004000400008 